\title{
Evaluation of Positional Change of Teeth Caused by the Use of an Anterior Partial Device: A Study by Computerized Tomography
}

\author{
Catiana Secundino Ralin de Araújo', Telma Guadalupe Piedade Ralin', José Eduardo Chorres Rodríguez², Lidia Audrey Rocha Valadas³ \\ Camila Costa Dias ${ }^{4}$, Antonio Sergio Guimaraes ${ }^{1}$ \\ 'São Leopoldo Mandic School of Dentistry, Campinas-SP, BRAZIL. \\ ${ }^{2} S$ chool of Dentistry, Federal University of Sergipe, Aracaju-SE, BRAZIL. \\ ${ }^{3}$ School of Dentistry, University of Buenos Aires, Buenos Aires, ARGENTINA. \\ ${ }^{4}$ School of Dentistry, Unichristus, Fortaleza-CE, BRAZIL.
}

\begin{abstract}
Objectives: The aim of this study was to analyze the possible correlation between using a partial coverage interocclusal plaque and the probability of changes in dental positioning. Methods: this is a transversal study, where twenty patients with temporomandibular muscle dysfunction (tmd) were selected in the city of aracaju-se-brazil, with both gender and aged over 18 years. The clinical examination was carried out by the research diagnostic criteria/tmd, patients were classified according to the subgroup of dysfunctions. Individuals classified as muscular tmd were positioned in the dental chair and submitted to orthodontic button bonding procedures on the buccal surface of the central incisors and on the first molars, in such a way that they served as a guide for overlapping tomographic images. Soon after, the anterior partial device was adapted to the antero-inferior teeth and the patients underwent cone-beam computed tomography. The research participants were instructed to use such a device daily, for eight hours, for a period of eight weeks and, thus, they were submitted
\end{abstract}

to a new tomographic image for later evaluation in three dimensions and measurement of the dental positioning modification, if it occurred. Results: in this study we observe no statistically significant association between the presence of tooth movement and the use of the partial cover plate. Conclusion: according to the results of this study, there was no statistical correlation between the use of the partial-coverage interocclusal plaque and the change in dental positioning for the period evaluated.

Key words: Interocclusal device, Partial coverage occlusal plaques, Full coverage occlusal plaques, Muscle tmd, Cone-beam tomography.

Correspondence

Ms. Camila Costa Dias

Postgraduate Program School of Dentistry, Unichristus, Fortaleza-CE, BRAZIL. Email: primoimplanto@gmail.com

DOI: 10.5530/jyp.2021.13.33

\section{INTRODUCTION}

Temporomandibular Disorder (TMD) is defined as a set of clinical problems involving the muscles of mastication, the Temporomandibular Joint (TMJ) and associated structures. Therefore, TMD are subdivided into TMJ disorders and masticatory muscle disorders. ${ }^{1,2}$

For the treatment of this condition, there are several therapeutic modalities reported in the literature, ranging from cognitive behavioral therapy, kinesiotherapy, thermotherapy, transutaneous electrical stimulation, dry needling and use of interocclusal plaques. ${ }^{1,3}$ The latter are believed to be beneficial in most cases of muscle TMD, as a conservative, reversible therapy that has great clinical success in controlling pain and functional disorders of the jaw. ${ }^{4}$

Interocclusal plaques can act by increasing stability between the maxilla and mandible, which can be basically divided into stabilizing (or permissive) interocclusal plaques and repositioning (or positioning) plaques..$^{5-7}$ These devices are used with diverse clinical applicability and with wide acceptance, promoting a better distribution of forces exerted on the mastication system and, in turn, they can minimize and even control the individuals' painful symptoms. ${ }^{6-8}$

The use of the anterior partial plate is usually performed at night. Thus, the alveolar structures receive regular daily stimulation when the patient performs functional movements without the device. However, there are controversies regarding the possibility of altering dental positioning due to its prolonged use. In the literature, there is no three-dimensional measurement of this change or even the scientific consensus on the existence of this event. Thus, without the clarity of the mechanism involved, clinicians choose to use such devices in a short time (three to four days at most), since the posterior teeth without contact could extrude and only the contact of the plate with the teeth previous ones, would cause intrusion. ${ }^{7,9}$

Plates are normally used as a therapeutic modality for muscular TMD, some cases of joint TMD and still preserve dental structure in patients with parafunctional habits; thus, it is considered one of the reversible and conservative methods for pain control, being consecrated in the literature since its idealization. They are described in the literature with different names such as relaxation plate, anterior bite devices, Lucia's JIG, NTI, relax, front plateau. ${ }^{9}$

A controversy in the literature is regarding the design of occlusal plaques; some authors prefer the use of partial coverage plaques because they also obtain control of painful symptoms, with greater simplicity in making them. ${ }^{7,10}$ Thus, the objective was to analyze the change in dental positioning after using an interocclusal plate with partial coverage for a period of eight weeks.

\section{MATERIALS AND METHODS}

\section{Ethical Aspects and Sample}

This work was approved by the Research Ethics Committee of the São Leopoldo Mandic Dental Research Center- Campinas-Brazil, under protocol no. 2011/0191. 
As inclusion criteria, individuals should present at least 18 years of age, at least 24 teeth maintained in the dental arch in conditions of integrity, presence of erupted permanent teeth antagonists, motor ability to position the Nociceptive Trigeminal Inhibition Tension Suppression System (NTI-tss) on the teeth; periodontal health and absence of dental caries. As an exclusion criterion, individuals could not be diagnosed with muscle TMD using RDC / TMD - Axis I. We exclude participants that don't fit the inclusion criteria. A total of 50 individuals were examined and after the exclusion criteria, 20 participants were selected.

\section{Clinical Examination}

The selected participants signed the Free and Informed Consent Form and filled out a form with demographic data and were examined in order to observe the oral health of the individuals and to check the number of dental units and whether they had antagonists.

Participants were referred for bonding orthodontic buttons (national / Morelli $^{\oplus}$ - Figure 1) on the buccal surface of the teeth, at a previously established height of $3.5 \mathrm{~mm}$ from the incisal edge to the base of the button on the central incisors and at $3.5 \mathrm{~mm}$ from the tip of the mesiobuccal cusp, along the long axis of this mesial cusp to the middle of the orthodontic button on the first molars, using a bracket positioner, bilaterally: first molar and central incisor, totaling four buttons in the upper arch of each individual, for this procedure conditioning with $35 \%$ phosphoric acid, washing with filtered water, drying, affixing the adhesive, light curing for $10 \mathrm{sec}$, placing the button with resin and light curing for $40 \mathrm{sec}$ Figures 2 and 3.

The partial coverage device NTI-tss was used for eight weeks, during the night, by all patients. This prefabricated device was repackaged with self-curing acrylic resin on the lower central incisors (as the buttons were positioned on the buccal portion of the upper teeth), and the incisal support area of the same coincided with the upper midline with just a touch of previous region. In addition, the NTI-tss maintained the shortest distance between the posterior teeth, without any contact between them in the lateral and opening and closing excursion movements (Figure 4).

Initially, a cone beam computed tomography (CBCT) was performed without the use of an interocclusal device, to check the initial position of the orthodontic button (The patient was seated with his head positioned between the source and the X-ray detector tube system in the maximum position) usual intercuspation). In a second phase after using the device for eight weeks, the individual underwent a new CBCT and both the initial and final images were evaluated by the same operator. To check whether the dental positioning changed, the cuts $(0.25$ voxel-FOV $8 \mathrm{~cm}$ - Kvp 120.00 - mA 36.12) were observed using the CBCT software Xoran

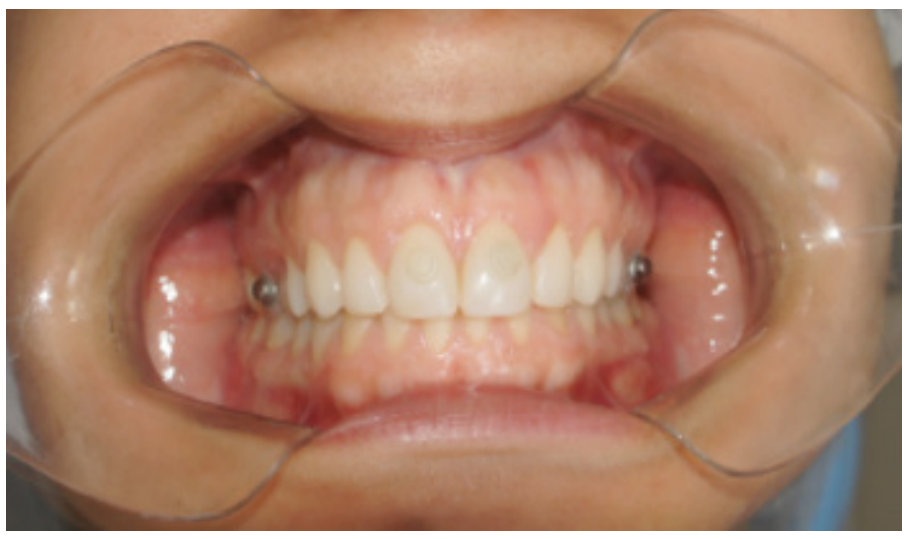

Figure 1: Intraoral photo showing the positioning of the orthodontic buttons on the buccal of the central incisors and on the mesiobuccal cusp of the first molars.
(Xoran Technologies, USA), between the points previously determined. With the initial multiplanar reconstruction work screen, the patient's volume was aligned following the anatomical references of the axial, sagittal and coronal planes in such a way as to leave the orbit-meatal plane (Frankfurt), oriented by the sagittal section, parallel to the plane horizontal to eliminate possible inclinations of the head, aligning the base of the bilateral mandible, in the coronal section, to the horizontal plane and the heads of the mandible, viewed through the axial section, in the same horizontal plane.

After selecting the images of each dental unit (maxillary central incisors and maxillary first molars), they were worked on in the i-CATvision program to perform measurements between orthodontic buttons using the measurement tool of the program. After eight weeks using the device, patients underwent a new CBCT. The images were obtained and selected again with the same standardization as the previous shot (using the previously installed orthodontic buttons as a reference).

In order to establish guidance points to measure possible changes in dental positioning, a pilot study was initially carried out aiming at such reliability. Of the 20 cases studied, the first 10 were selected and anatomical points of orientation were established in two groups:

Group 1 - Measurement in the upper incisors: from the end of the anterior nasal spine to half of the orthodontic button and in the molars, from the apex of the maxillary sinus to half of the orthodontic button;

Group 2 - Measurement in the upper incisors: from the end of the buccal bone plate, to the half of the orthodontic button and in the molars, from the end of the buccal bone plate, to the half of the orthodontic button.

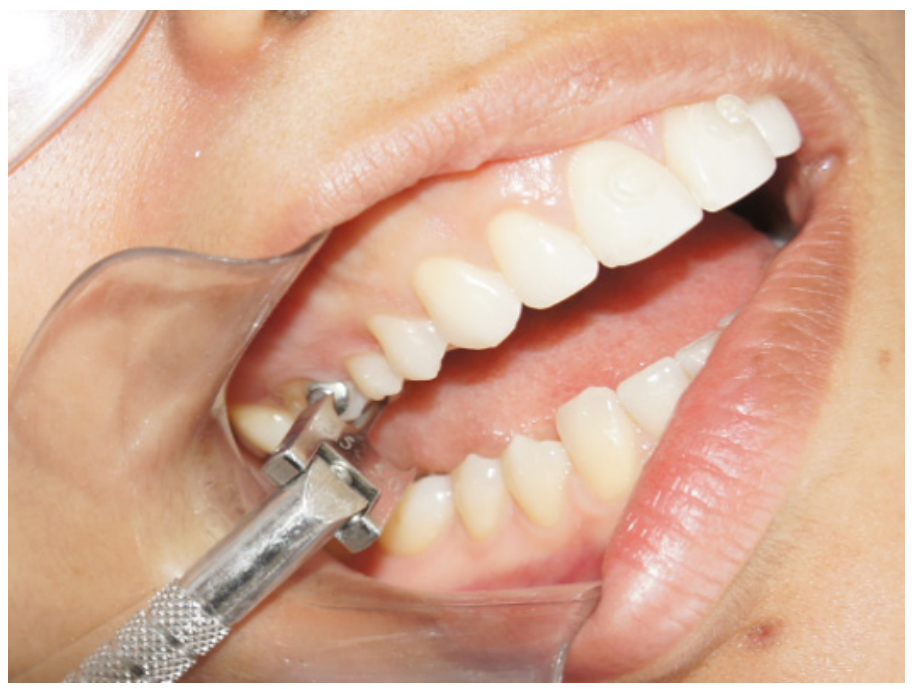

Figure 2: Positioning of orthodontic buttons in the vestibular of the central incisors; $3.5 \mathrm{~mm}$ from the incisal base to the base of the orthodontic button.

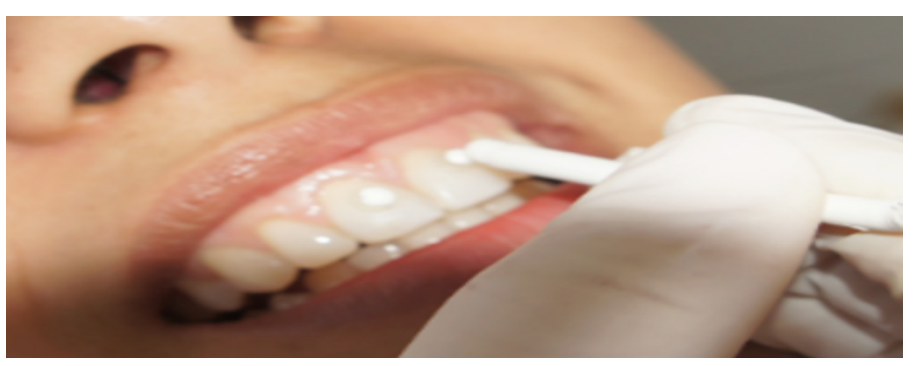

Figure 3: Positioning of the orthodontic buttons in the buccal of the first molars; $3.5 \mathrm{~mm}$ from the mesiobuccal cusp to the middle of the orthodontic button. 
Therefore, the following measures were determined: from the center of the orthodontic button to the final limit of the buccal bone plate of the upper central incisors and from the center of the orthodontic button to the final limit of the buccal bone plate of the first molars. Such measurement was performed and the data archived for later statistical analysis.

Patients were exposed to radiation from CBCT (Figure 5), without overlapping or interfering with anatomical structures of the temporomandibular joint, allowing a more specific assessment of possible injuries that are not commonly seen in routine clinical examination. In cases where the presence of any type of injury was detected, it would be referred to the emergency department at the Federal University of Sergipe for treatment.

\section{Statistical Analysis}

The results were tabulated and submitted to Student's $t$-test with a 95\% significance level. The statistical program SPSS version 15.0 for Windows was used for all statistical analyzes.

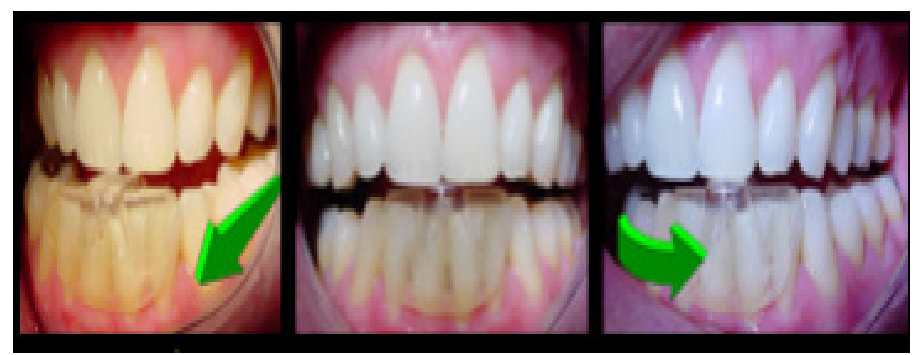

Figure 4: Photograph of the patient performing functional excursion movements using the NTI-tss.

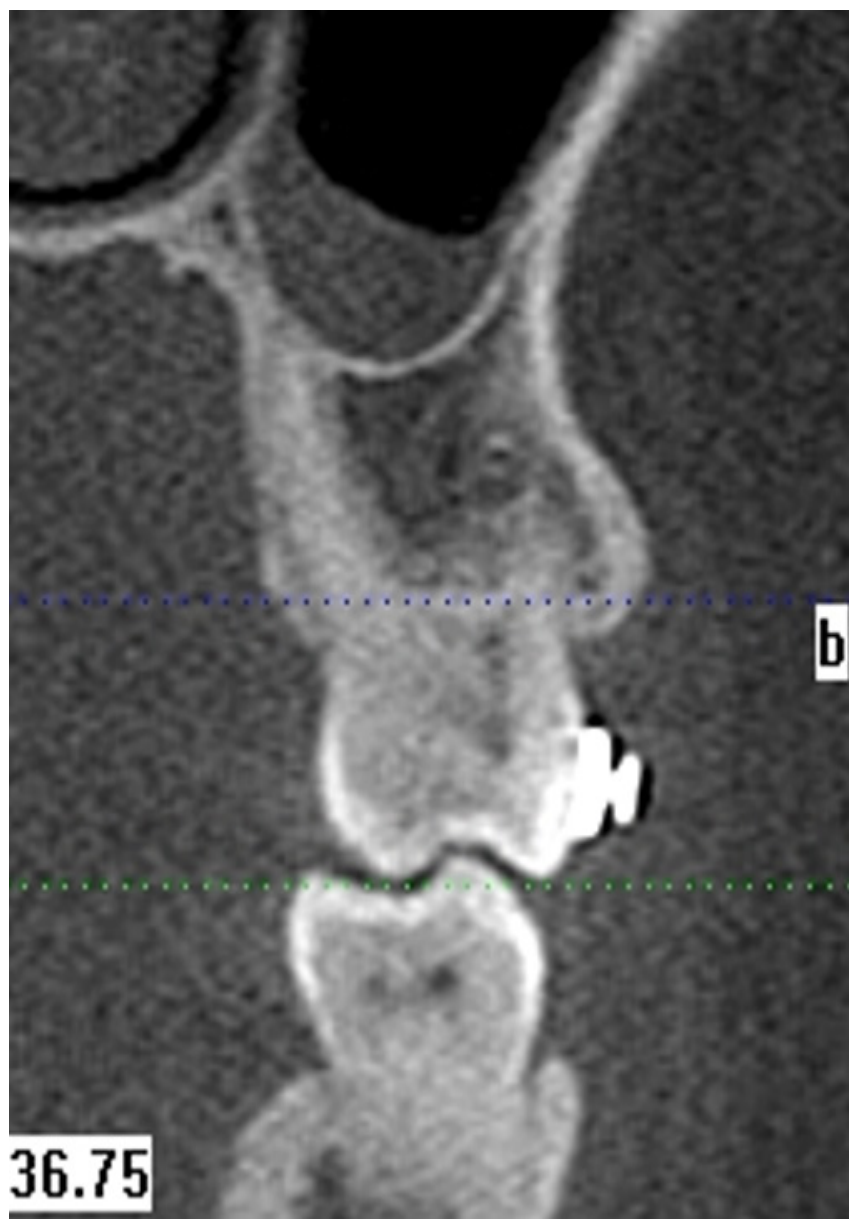

Figure 5: Longitudinal section of the first molar of a volunteer.

Table 1: Distribution of measurements of the first maxillary molars (before and after eight weeks) of the female gender.

\begin{tabular}{|c|c|c|c|c|c|c|c|}
\hline \multicolumn{8}{|c|}{ Measurements and Variations of the $1^{\text {st }}$ Right and Left Molar of the Female Gender in Pre and Post } \\
\hline \multirow{2}{*}{$\begin{array}{c}\text { Gender } \\
\text { Age }\end{array}$} & \multicolumn{3}{|c|}{$1^{\text {st }}$ Molar Right Button } & \multirow{2}{*}{$\begin{array}{l}\text { Gender } \\
\text { Idade }\end{array}$} & \multicolumn{3}{|c|}{$1^{\text {st }}$ Molar Left Button } \\
\hline & Pre $(\mathrm{mm})$ & $\begin{array}{l}\text { Post } \\
(\mathrm{mm})\end{array}$ & $\begin{array}{l}\text { (Pre- } \\
\text { Post)\% }\end{array}$ & & Pre $(\mathrm{mm})$ & $\begin{array}{l}\text { Post } \\
\text { (mm) }\end{array}$ & $\begin{array}{l}\text { (Pre- } \\
\text { Post)\% }\end{array}$ \\
\hline $\mathrm{FEM} / 20$ & 9.855 & 10.293 & $-4.4 \%$ & $\mathrm{FEM} / 20$ & 9.313 & 9.671 & $-3.8 \%$ \\
\hline $\mathrm{FEM} / 23$ & 12.059 & 12.059 & $0.0 \%$ & $\mathrm{FEM} / 23$ & 13.432 & 13.432 & $0.0 \%$ \\
\hline $\mathrm{FEM} / 25$ & 5.911 & 6.404 & $-8.3 \%$ & FEM/25 & 6.278 & 6.716 & $-7.0 \%$ \\
\hline $\mathrm{FEM} / 26$ & 12.289 & 12.728 & $-3.6 \%$ & FEM/26 & 12.576 & 12.576 & $0.0 \%$ \\
\hline $\mathrm{FEM} / 27$ & 11.001 & 11.001 & $0.0 \%$ & FEM/27 & 13.140 & 13.140 & $0.0 \%$ \\
\hline $\mathrm{FEM} / 30$ & 10.511 & 10.699 & $-1.8 \%$ & FEM/30 & 10.512 & 10.731 & $-2.1 \%$ \\
\hline $\mathrm{FEM} / 34$ & 13.464 & 13.528 & $-0.5 \%$ & FEM/34 & 14.453 & 14.453 & $0.0 \%$ \\
\hline FEM/35 & 14.717 & 14.717 & $0.0 \%$ & FEM/35 & 15.242 & 15.242 & $0.0 \%$ \\
\hline FEM/44 & 12.702 & 12.702 & $0.0 \%$ & FEM/44 & 12.808 & 12.808 & $0.0 \%$ \\
\hline FEM/49 & 14.016 & 14.454 & $-3.1 \%$ & FEM/49 & 12.410 & 12.410 & $0.0 \%$ \\
\hline
\end{tabular}




\section{RESULTS}

The research consisted of 20 individuals, 10 females (50\%) and 10 males (50\%), with an average age of 31.3 years.

The pilot study did not observe significant statistics between groups. We opted for the point closest to the orthodontic button so that in a greater number of individuals, the possibility of greater alteration in greater distances to be measured was reduced.

Comparison of the measurements of Group 1 and Group 2 in relation to the anatomical points determined (Tables 1-4):

About the distribution of the difference in the measurements of the teeth, on the Table 5, we just observe significance on the group of females with right button incisor $(p=0.035)$.

\section{DISCUSSION}

Twenty individuals with painful symptoms, with an average age of 18 to 50 years, used the NTI-tss device for eight hours daily and were followed up for eight weeks in order to investigate whether there would be a change in dental positioning.

With the emergence of NTI for the treatment of TMD, studies began to be carried out to prove its effectiveness, ${ }^{7}$ however studies on possible dental changes are scarce. The findings of this study are in agreement with Palla, ${ }^{11}$ Carlsson ${ }^{12}$ and Dawson, ${ }^{13}$ who point out a greater complaint of pain inserted in the age group of middle-aged individuals. In the present study, greater reliability was observed in the results in relation to the male gender, since there was only statistical difference in the female gender, when the right central incisor was evaluated; in general, occlusal changes were not statistically significant.

Magnusson et al. ${ }^{14}$ described occlusal changes in patients who used NTI-tss for a period of three to six months, where occlusal changes were related to a smaller number of occlusive teeth. Similar findings were pointed out by studies such as that by Jokstad et al..${ }^{15}$ Miranda,${ }^{16}$ Conti et al. ${ }^{17}$ and Fricton, ${ }^{18}$ who also defend the idea that possible occlusal changes may occur due to the use of partial coverage plates. However, Alencar ${ }^{19}$ demonstrated in his study that, if a protocol of partial use of occlusal devices was elaborated, irreversible occlusal changes in groups of patients with myofascial pain were avoided. In the present study, no occlusal changes were found that prevent the use of the anterior partial device in patients with TMD. Probably, if the partial cover plate had been used for a long time, without guidance for use, some type of considerable occlusal alteration that interfered with the dynamics of the mandibular movements could be noticed.

Bergstrom et al. ${ }^{20}$ observed that half of the patients who have an interocclusal device for TMD control, continued to use it regularly for an average period of thirty months during the night even after therapy. This indiscriminate use may be one of the factors that point to these changes. In the present study, no evidence of tooth movement was observed for an eight-week period, however, long-term studies are needed to support the clinic on the question of using the partial cover plate for a longer period of time and to raise the question of what would be the real need to use such devices for a long period of time after therapy. Although the manufacturer of the NTI-tss indicates the use of the device continuously or in a short period of time, this does not relieve the patient from regularly visiting the dental office for evaluation and follow-up, avoiding the indiscriminate use of the device.

When considering that the recommended use in cases of TMD is the use of the partial coverage device for a short period of time, on average three to four days, for a period of up to eight hours daily, concerns about changes in dental positioning do not it must be an issue.

Erbasar et al..$^{21}$ evaluated for six weeks the effectiveness of the association with the use of NTI-tss concomitant with first-line myofascial pain therapy, which includes guidance, assurance, counseling and behavioral changes in relieving TMD symptoms in 40 individuals. There was no statistically significant difference in pain control when compared to the control group. Bruno and Krymchantowski ${ }^{22}$ evaluated the efficacy of NTI-tss in the preventive treatment of migraine by comparing pharmacological therapy with amitriptyline and non-occlusal palatal plaque after 6 and 12 weeks of treatment. In this study, the group treated with NTI-tss obtained results similar to non-occlusal plaque and both inferior to amitriptyline. Conti et al. ${ }^{23}$ compared the use of NtI-tss in pain control to occlusal plaque and behavioral therapy. Follow-ups were performed after 2 weeks, 6 weeks and 3 months, noting that behavioral therapy only showed results after 3 months, while the others in 2 weeks

Table 2: Distribution of male first molar measurements (before and after eight weeks).

\begin{tabular}{|c|c|c|c|c|c|c|c|}
\hline \multicolumn{8}{|c|}{ Measurements and Variations of the $1^{\text {st }}$ Right and Left Molar of the Female Gender in Pre and Post } \\
\hline \multicolumn{8}{|c|}{ Medições e Variações do $1^{\circ}$ e $1^{\circ}$ Molar Direito e Esquerdo do Gênero Masculino no Pré e no Pós } \\
\hline \multirow{2}{*}{$\begin{array}{c}\text { Gender } \\
\text { Age }\end{array}$} & \multicolumn{3}{|c|}{$1^{\text {st }}$ Molar Right Button } & \multirow{2}{*}{$\begin{array}{c}\text { Gender } \\
\text { Age }\end{array}$} & \multicolumn{3}{|c|}{$1^{\text {st }}$ Molar Left Button } \\
\hline & $\begin{array}{l}\text { Pre } \\
(\mathrm{mm})\end{array}$ & $\begin{array}{l}\text { Post } \\
(\mathrm{mm})\end{array}$ & $\begin{array}{l}\text { (Pre- } \\
\text { Pós)\% }\end{array}$ & & $\begin{array}{l}\text { Pre } \\
(\mathrm{mm})\end{array}$ & $\begin{array}{l}\text { Post } \\
(\mathrm{mm})\end{array}$ & (Pre-Post)\% \\
\hline MAS/19 & 12.201 & 12.201 & $0.0 \%$ & MAS/19 & 29.894 & 29.894 & $0.0 \%$ \\
\hline MAS/20 & 11.658 & 11.658 & $0.0 \%$ & MAS/20 & 10.030 & 10.030 & $0.0 \%$ \\
\hline $\mathrm{MAS} / 24$ & 12.848 & 12.994 & $-1.1 \%$ & $\mathrm{MAS} / 24$ & 10.658 & 10.658 & $0.0 \%$ \\
\hline MAS/25 & 12.972 & 12.972 & $0.0 \%$ & MAS/25 & 13.403 & 13.403 & $0.0 \%$ \\
\hline $\mathrm{MAS} / 26$ & 18.133 & 18.133 & $0.0 \%$ & $\mathrm{MAS} / 26$ & 14.191 & 18.396 & $-29.6 \%$ \\
\hline MAS/26 & 12.089 & 12.089 & $0.0 \%$ & MAS/26 & 15.549 & 15.549 & $0.0 \%$ \\
\hline MAS/27 & 8.071 & 8.071 & $0.0 \%$ & MAS/27 & 7.884 & 8.176 & $-3.7 \%$ \\
\hline MAS/44 & 15.106 & 15.599 & $-3.3 \%$ & MAS/44 & 15.204 & 15.204 & $0.0 \%$ \\
\hline MAS/44 & 15.767 & 15.955 & $-1.2 \%$ & MAS/44 & 14.717 & 14.717 & $0.0 \%$ \\
\hline MAS/58 & 7.696 & 7.696 & $0.0 \%$ & MAS/58 & 13.140 & 13.140 & $0.0 \%$ \\
\hline
\end{tabular}


Table 3: Distribution of measurements of central incisors (before and after eight weeks) for females.

\begin{tabular}{cccccccc}
\hline \multicolumn{5}{c}{ Measurements and Variations of the Right and Left Female Incisor in Pre and Post } \\
\hline Gender & \multicolumn{2}{c}{ Right Button Incisor } & Gender & \multicolumn{2}{c}{ Left Button Incisor } \\
\hline Age & Pre $(\mathrm{mm})$ & $\begin{array}{c}\text { Post } \\
(\mathrm{mm})\end{array}$ & $\begin{array}{c}\text { (Pre- } \\
\text { Pós)\% }\end{array}$ & Age & Pre (mm) & $\begin{array}{c}\text { Post } \\
(\mathrm{mm})\end{array}$ & $\begin{array}{c}\text { (Pre- } \\
\text { Pós) } \%\end{array}$ \\
\hline FEM/20 & 12.410 & 12.264 & $1.2 \%$ & FEM/20 & 12.702 & 12.702 & $0.0 \%$ \\
FEM/23 & 10.731 & 10.622 & $1.0 \%$ & FEM/23 & 11.101 & 11.101 & $0.0 \%$ \\
FEM/25 & 7.048 & 7.048 & $0.0 \%$ & FEM/25 & 7.280 & 7.280 & $0.0 \%$ \\
FEM/26 & 13.183 & 13.183 & $0.0 \%$ & FEM/26 & 13.990 & 12.630 & $9.7 \%$ \\
FEM/27 & 13.139 & 13.139 & $0.0 \%$ & FEM/27 & 10.699 & 10.699 & $0.0 \%$ \\
FEM/30 & 7.275 & 7.275 & $0.0 \%$ & FEM/30 & 16.031 & 16.031 & $0.0 \%$ \\
FEM/34 & 13.578 & 13.227 & $2.6 \%$ & FEM/34 & 13.514 & 13.139 & $2.8 \%$ \\
FEM/35 & 11.680 & 11.534 & $1.2 \%$ & FEM/35 & 16.951 & 16.031 & $5.4 \%$ \\
FEM/44 & 13.250 & 13.250 & $0.0 \%$ & FEM/44 & 16.092 & 16.092 & $0.0 \%$ \\
FEM/49 & 12.848 & 12.848 & $0.0 \%$ & FEM/49 & 14.806 & 14.806 & $0.0 \%$ \\
\hline
\end{tabular}

Table 4: Distribution of measurements of central incisors (before and after eight weeks) of the male gender.

\begin{tabular}{cccccccc}
\hline \multicolumn{5}{c}{ Measurements and Variations of the Right and Left Female Incisor in Pre and Post } \\
\hline Gender & \multicolumn{2}{c}{ Right Button Incisor } & Gender & \multicolumn{3}{c}{ Left Button Incisor } \\
\hline Age & Pré $(\mathrm{mm})$ & Pós (mm) & $\%$ & Age & Pré (mm) & Pós (mm) & $\%$ \\
\hline MAS/19 & 13.300 & 13.136 & $1.2 \%$ & MAS/19 & 13.578 & 13.578 & $0.0 \%$ \\
MAS/20 & 9.198 & 9.198 & $0.0 \%$ & MAS/20 & 8.322 & 8.322 & $0.0 \%$ \\
MAS/24 & 13.464 & 13.464 & $0.0 \%$ & MAS/24 & 12.388 & 12.201 & $1.5 \%$ \\
MAS/25 & 14.614 & 12.151 & $16.9 \%$ & MAS/25 & 12.118 & 12.118 & $0.0 \%$ \\
MAS/26 & 13.578 & 13.552 & $0.2 \%$ & MAS/26 & 14.191 & 14.191 & $0.0 \%$ \\
MAS/26 & 12.707 & 12.707 & $0.0 \%$ & MAS/26 & 13.957 & 13.793 & $1.2 \%$ \\
MAS/27 & 9.636 & 9.417 & $2.3 \%$ & MAS/27 & 9.760 & 9.760 & $0.0 \%$ \\
MAS/44 & 17.345 & 17.345 & $0.0 \%$ & MAS/44 & 16.556 & 16.556 & $0.0 \%$ \\
MAS/44 & 18.133 & 18.396 & $-1.5 \%$ & MAS/44 & 15.505 & 15.505 & $0.0 \%$ \\
MAS/58 & 9.688 & 9.524 & $1.7 \%$ & MAS/58 & 11.494 & 11.330 & $1.4 \%$ \\
\hline
\end{tabular}

Table 5: Distribution of the difference in the measurements of the teeth.

\begin{tabular}{ccc}
\hline Gender Female & p-value & Difference \\
\hline Right button incisor (pre and post) & 0.035 & Significant \\
Left button incisor (pre and post) & 0.073 & Not significant \\
Gender Male & & Not significant \\
Right button incisor (pre and post) & 0.145 & Not significant \\
Left button incisor (pre and post) & 0.267 & Not significant \\
Gender Female & & Not significant \\
1st Molar right button (pre and post) & 0.992 & \\
2nd Molar right button (pre and post) & 0.500 & Not significant \\
Gender Male & & Not significant \\
1st Molar right button (pre and post) & 0.931 & 0.835 \\
2nd Molar right button (pre and post)
\end{tabular}


already relieved the pain. Al Moraissi et al. ${ }^{24}$ through a systematic review and meta-analysis evaluated the efficacy of several types of occlusal plaque in the treatment of TMD, confirming that in 48 clinical trials the evidence was of very low to moderate quality, without studies with high level of evidence.

Some studies point to potential side effects, caused by the indiscriminate use of the partial coverage device $e^{13-15,18}$ the last two groups of authors reported transient pain and / or anteroinferior dental sensitivity in the research participants after using the device, a situation reported by one of the participants in the present study. Another eight patients reported muscle incoordination when waking up and removing the partial coverage device of the NTI-tss type, having difficulty closing their mouths at first, agreeing with the findings of Magnusson et al. ${ }^{14}$

In this study, only patients with muscle TMD were selected using the RDC / TMD. The classification system proposed by the RDC / TMD is easy to understand and allows a standardization of clinical findings in population surveys. ${ }^{25,26}$ It is known that there are several studies that describe the therapeutic effect of plaques on the symptomatological control of muscle TMDs, however, the findings in the literature point more to data on the relief of painful symptoms in the masticatory muscles and not about possible effects, which have not yet been fully elucidated. . $^{511,14,18}$

Some of the limitations of the study were the sample number, given that the cone beam tomography exam is expensive and the follow-up time is only eight weeks, thus suggesting that new controlled longitudinal studies that assess the long-term effects should be performed.

\section{CONCLUSION}

On this study, there was no statistical correlation between the use of the partial-coverage interocclusal plaque and the change in dental positioning for the period evaluated.

\section{ACKNOWLEDGEMENT}

We acknowledge the participants of this study.

\section{CONFLICT OF INTEREST}

The authors declare no conflict of interest.

\section{ABBREVIATIONS}

TMD: Temporomandibular disorder; TMJ: Temporomandibular joint; NTI-tss: Nociceptive Trigeminal Inhibition Tension Suppression System; RDC: Research Diagnostic Criteria; CBCT: Cone beam computed tomography.

\section{REFERENCES}

1. Leew R. Dor Orofacial. Guia de avaliação, diagnóstico e tratamento. 4st ed. São Paulo: Quintessence; 2010.

2. Cidrão ALM, Guimarães AS. Prevalence of Temporomandibular Dysfunction Symptoms in Dental Surgeons. J Young Pharm. 2019;11(4):424-8.

3. Vasconcelos RSN, Marques LARV, Kuehner MCP, Barroso KSN, Dias CC, Carmo FJRLD, et al. Fisioterapia na disfunção temporomandibular. Revista Saúde. 2019;45(2):1-13.

4. Radanović $B$, Vučinić $P$, Janković T, Mahmutović $E$, Penjašković $D$. Musculoskeletal symptoms of the neck and shoulder among dental practitioners. J Back
Musculoskelet Rehabil. 2017;30(4):675-9.

5. Stapelmann H, Türp JC. The NTI-tss device for the therapy of bruxism, temporomandibular disorders, and headache-where do we stand? A qualitative systematic review of the literature. BMC Oral Health. 2008;29(8):22.

6. Melo GM. Mecanismo de ação dos dispositivos interoclusais. RSBO. 2010;7(2):216-25.

7. Oliveira SSI, Pannuti CM, Paranhos KS, Tanganeli JPC, Laganá DC, Sesma N et al. Effect of occlusal splint and therapeutic exercises on postural balance of patients with signs and symptoms of temporomandibular disorder. Clinical and Experimental Dental Research. 2018;1:1-7.

8. BadelT, Marotti M, Kern J, Laskarin M. A quantitative analysis of splint therapy of displaced temporomandibular joint disc. Ann Anat. 2009;191(3):280-7.

9. Alqutaibi AY, Aboalrejal AN. Types of occlusal splint in management of temporomandibular disorders (TMD). J Arthritis. 2015;4(176):2.

10. Pegado LFR, Silva FL, Grossmann E, Guimarães AS. The approval rating through the use of an interocclusal device. RGO: Revista Gaúcha de Odontologia. 2013;61(1):85-91.

11. Palla S. Trigger points as a cause of Orofacial pain. Journal of Musculoskeletal Pain. 2004;12(3-4):29-36.

12. Carlsson GE. Temporomandibular joint disorders. In: Functional Occlusion in Restorative Dentistry and Prosthodontics. Mosby. 2016;161-71.

13. Dawson P. Oclusão Funcional: Da ATM ao desenho do sorriso. 1st ed. São Paulo: Santos; 2008.

14. Magnusson T, Adiels AM, Nilsson HL, Helkimo M. Treatment effect on signs and symptoms of temporomandibular disorders: Comparison between stabilization splint and a new type of splint (NTI). A Pilot study Swed Dent J. 2004;28(1):1120.

15. Jokstad A, Mo A, Krogstad BS. Clinical comparison between two different splint designs for temporomandibular disorder therapy. Acta Odontol Scand. 2005:63(4):218-26.

16. Miranda ME, Teixeira ML. A utilização das placas oclusais no controle das disfunções temporomandibulares (DTM). In: Congresso Internacional de Odontologia de São Paulo. 2007;1(1):25.

17. Conti PC, dos Santos CN, Kogawa EM, de Castro Ferreira Conti AC, de Araujo $\mathrm{CR}$. The treatment of painful temporomandibular joint clicking with oral splints: A randomized clinical trial. J Am Dent Assoc. 2006;137(8):1108-14.

18. Fricton J. Myogenous temporomandibular disorders: diagnostic and management considerations. Dent Clin North Am. 2007;51(1):61-83.

19. Alencar EN. Avaliação da eficácia em curto prazo do uso de placas estabilizadoras oclusais de cobertura total e dispositivos NTI (nociceptive trigeminal inhibitory splint) no tratamento da dor miofascial da musculatura mastigatória. PhD Thesis, Universitu of São Paulo. 2011.

20. Bergstrom I, List T, Magnusson T. A follow-up study of subjective symptoms of temporomandibular disorders in patients who received acupuncture and/ or interocclusal appliance therapy 18-20 years earlier. Acta Odontol Scand. 2008;66(2):88-92

21. Erbasar GNH, Alpaslan C Inan EG. Can an NTI-TSS device be effective as a first-line therapy in patients with TMD myofascial pain?. Journal of Oral Rehabilitation. 2017;44(8):589-93.

22. Bruno MAD, Krymchantowski AV. Amitriptyline and intraoral devices for migraine prevention: A randomized comparative trial. Arq Neuropsiquiatr. 2018;76(4):213-8.

23. Conti PC, Corrêa AS, Lauris JR, Stuginski-Barbosa J. Management of painful temporomandibular joint clicking with different intraoral devices and counseling: a controlled study. J Appl Oral Sci. 2015;23(5):529-35.

24. Al-Moraissi EA, Farea R, Qasem KA, Al-Wadeai MS, Al-Sabahi ME, AlIryani GM. Effectiveness of occlusal splint therapy in the management of temporomandibular disorders: Network meta-analysis of randomized controlled trials. Int J Oral Maxillofac Surg. 2020;49(8):1042-56

25. Dodić $S$, Sinobad $V$, Obradović-Djuricić K, Medić $V$. The role of occlusal factor in the etiology of temporomandibular dysfunction. Srp Arh Celok Lek. 2009:137(11 12):613-8.

26. Schiffman E, Ohrbach R, Truelove E, Look J, Anderson G, Goulet JP, et al. International RDC/TMD Consortium Network, International Association for Dental Research; Orofacial Pain Special Interest Group, International Association for the Study of Pain. Diagnostic Criteria for Temporomandibular Disorders (DC/TMD) for Clinical and Research Applications: Recommendations of the International RDC/TMD Consortium Network* and Orofacial Pain Special Interest Groupt. J Oral Facial Pain Headache. 2014;28(1):6-27. 